REFERENCES AND/OR ACKNOWLEDGEMENTS

1. Satti $A E$, et al. Impact of clinical pharmacist interventions in the medical ward-a study at Alkhor Hospital. Am J of PharmTech Res 2014

No conflict of interest.

\section{CPS-162 PHARMACEUTICAL INTERVENTIONS IN DRUGS PROVIDED TO THE OUTPATIENT HOSPITAL PHARMACY}

A Brito*, A Fernandes, L Lourenço, S Domingos, A Alcobia.

10.1136/ejhpharm-2020-eahpconf.263

Hospital Garcia De Orta, Pharmacy, Almada, Portugal

Background and importance Pharmacists are responsible for outpatient drug distribution. The aim is not just to provide the medication but also to prevent, acknowledge and resolve medication related problems (MRP). The value of pharmaceutical interventions (PIs) is reflected in adherence, healthcare education and promotion of quality of life in patient.

Aim and objectives To assess and characterise PIs performed in outpatients, their caregivers and other healthcare professionals.

Material and methods This was a retrospective longitudinal study conducted in all patients treated in the outpatient hospital pharmacy between November 2018 and August 2019. PIs were recorded and classified according to type, reason, time and outcome of the intervention.

Results During the study period, 663 PIs ( $\mathrm{n}=38057$ patients) were recorded. The specialties with the largest number of interventions were infectious disease $(41.9 \%)$, oncology $(26.5 \%)$ and gastroenterology (14.6\%). The PI targets were patients $(62.7 \%)$, caregivers (12.2\%), physicians (22.9\%) and other healthcare professionals $(2.2 \%)$. We highlighted PIs related to therapeutic education (37.1\%), verification/reinforcement of adherence (21.1\%) and pharmaceutical consultation (7.4\%). The most relevant reasons for PIs were new patient/new drug (44.5\%), poor adherence $(21.5 \%)$, incorrect intake/insufficient therapy knowledge (4.9\%), wrong drug prescribed $(4.1 \%)$ and suspected adverse drug reaction (1.1\%). A total of $67.3 \%$ of PIs took 5$15 \mathrm{~min}$ and $19.1 \%>15 \mathrm{~min}$. The acceptance rate of pharmaceutical recommendations was $92.9 \%$.

Conclusion and relevance Pharmacists are essential when dispensing drugs, not only for providing information and therapeutic teaching, but also to actively detect MRP. Due to the high number of daily consultations performed (about 200 patients/day) and lack of human resources, it is likely that PIs are underreported. Communication between different health professionals is essential in the resolution of MRP, contributing to safety improvements and therapy optimisations. PIs had a high acceptance rate which demonstrates the importance and recognition of the pharmacist's role.

\section{REFERENCES AND/OR ACKNOWLEDGEMENTS}

1. Boorman $S$, et al. Another way forward for pharmaceutical care: a team-based clinical pharmacy service. Pharm J 2000;264

No conflict of interest.

\section{CPS-163 CLINICAL PHARMACIST RESIDENCE IN AN INTENSIVE CARE UNIT: SCOPE AND RELEVANCE}

T Cabeças*, J Cardoso, R Oliveira, M Pereira. Cuf Infante Santo, Pharmacy, Lisboa, Portugal
Background and importance The clinical pharmacist ensures the effective and rational use of drugs through the application of technical and scientific knowledge. Residence in the intensive care unit (ICU) allows greater proximity to the patient and the multidisciplinary team, resulting in rapid and efficient support in all issues related to drugs.

Aim and objectives To describe and characterise the interventions developed by the clinical pharmacist residing in the ICU, and thereby demonstrate its added value, namely in pharmacotherapeutic follow-up and on the spot rapid and assertive support in a multidisciplinary environment.

Material and methods The clinical pharmacist's workplace was transferred to the ICU of a private hospital in Lisbon, with 12 inpatient beds. Ove a 10 month period (November 2018 to August 2019), the unit had a monthly average of 165 inpatients, of which 115 (70\%) were in postoperative recovery and $50(30 \%)$ in a critical condition. All pharmaceutical interventions for critically ill patients were recorded (Excel file and/or BSimple software), categorised and analysed.

Results Nearly $79 \%$ of critically patients admitted during the study period were the subject of pharmaceutical interventions, performing a total of 394: 86 (17\%) related to dose and dosage adjustments; 49 (10\%) related to dilution/reconstitution; $46(9 \%)$ were regarding training and preparation of technical and scientific support material; 44 (9\%) related to route of administration; 40 (8\%) related to logistics and supply issues; $30(6 \%)$ were interactions, compatibility and stability; $27(5 \%)$ were in the field of clinical nutrition; 19 (4\%) were related to records of drug allergies; $18(4 \%)$ were support in the establishment of guidelines based therapy; 13 (3\%) were internal audits of narcotic drugs, blood products and emergency vehicles; $11(2 \%)$ were clarification of questions on wound care material; 7 (1\%) were requests for out of hospital medication; and $4(1 \%)$ were therapeutic reconciliations.

Conclusion and relevance Residence of the clinical pharmacist in the ICU is fundamental for safe and effective use of drugs. The evidence presented in this study demonstrated the added value of providing a patient centred pharmaceutical service in a multidisciplinary and interdisciplinary team, adding value to the care provided by other health professionals. This proximity also allowed quick intervention in the resolution of various day to day pharmacotherapeutic and/or circuit related issues.

\section{REFERENCES AND/OR ACKNOWLEDGEMENTS}

No conflict of interest.

\section{CPS-164 A SAFE HANDLING HAZARDOUS DRUGS STRATEGY TO IMPROVE THE SAFETY OF HEALTH PROFESSIONALS: REDUCING EXPOSURE BY MEDICAL PRESCRIPTION REVIEW IN NURSING HOMES}

${ }^{1}$ I Cañamares Orbis* , ${ }^{1} \mathrm{~F}$ Apolo Carvajal, ${ }^{1} \mathrm{M}$ Gonzalez Martinez, ${ }^{1} \mathrm{E}$ Capilla Santamaria, ${ }^{1} \mathrm{~N}$ Martinez Casanova, ${ }^{1} \mathrm{I}$ Mayorga Bajo, ${ }^{1} \mathrm{~B}$ Caliz Hernandez, ${ }^{1} \mathrm{MT}$ Llanos Garcia, ${ }^{1} \mathrm{~A}$ Escudero Brocal, ${ }^{2} \mathrm{H}$ Hernandez Ovejero, ${ }^{1} \mathrm{~A}$ Aranguren Oyarzabal. 'Servicio Madrileño De Salud, Subdirección General De Farmacia Y Productos Sanitarios, Consejería De Sanidad., Madrid, Spain; ${ }^{2}$ Consejería De Políticas Sociales-Familias-Igualdad Y Natalidad, Agencia Madrileña De Atencion Social, Madrid, Spain

\subsection{6/ejhpharm-2020-eahpconf.265}

Background and importance The occupational risk due to exposure to hazardous drugs (HDs) has been a mounting concern to healthcare professionals, including in nursing homes. 